\title{
Empirical Analysis of Technical Efficiency of Chinese Aerospace Manufacturing
}

\author{
Yun Li \\ Jinan University, Guangzhou, China \\ Email: liiyunn@163.com
}

How to cite this paper: Li, Y. (2020). Empirical Analysis of Technical Efficiency of Chinese Aerospace Manufacturing. Modern Economy, 11, 807-816. https://doi.org/10.4236/me.2020.114060

Received: February 23, 2020

Accepted: April 13, 2020

Published: April 16, 2020

Copyright $\odot 2020$ by author(s) and Scientific Research Publishing Inc. This work is licensed under the Creative Commons Attribution International License (CC BY 4.0).

http://creativecommons.org/licenses/by/4.0/

\begin{abstract}
This paper constructs panel data using relevant data on aerospace manufacturing in 17 provinces and cities in China from 2010 to 2015. The B-C (1995) model was established using the SFA method. A trans-log production function model is used to analyze and study the technical efficiency of China's aerospace manufacturing industry. Then we analyze the technical efficiency of Chinese aerospace manufacturing industry. The research results show that: First, the overall technical efficiency of Chinese Aerospace manufacturing industry is at a moderately high level, with an average technical efficiency of 0.8673. Second, the increase in export delivery value and sales revenue of new products has a relatively weak impact on the improvement of technological efficiency. Third, the R \& D equivalent to full-time equivalent and the addition of fixed assets will significantly affect the technical efficiency of China's aerospace manufacturing industry. Finally, this article puts forward some policy suggestions based on the research results.
\end{abstract}

\section{Keywords}

Technical Efficiency, Aerospace Manufacturing, Stochastic Frontier Analysis (SFA)

\section{Introduction}

The aerospace manufacturing industry is the embodiment of a country's highly productive development. It represents the comprehensive national strength of a country and is an industry with high investment, high innovation, high technology, high risk, and high returns. The important characteristics of the aerospace manufacturing industry are intensive knowledge and technology, huge growth potential, strong employment capacity, and high industrial relevance. This industry is also an important force necessary to promote the transformation of 
Chinese economic development mode and industrial structure adjustment. Aerospace manufacturing is a typical high-tech industry in China. The industry is at the top of advanced equipment manufacturing. It has an irreplaceable status and role in the modernization of national economy and national defense. It has great strategic significance for the rapid development of Chinese economy and society.

Chinese Aerospace manufacturing has a history of more than sixty years. Great progress has been made in this development process. However, compared with developed countries, its shortcomings have gradually emerged. For example, the gap between independent innovation capabilities is vast, and there is a lack of innovation motivation and environment. Without the core technology of independent intellectual property rights, its competitive advantage is relatively weak. In the context of rough technology, the efficiency of technological innovation is mainly driven by the addition of new inputs. Therefore, the output efficiency is relatively low. These are major obstacles affecting the transformation and upgrading of Chinese Aerospace manufacturing industry and the development process of "military-civilian integration". Therefore, the efficiency of industrial development, especially technical efficiency, has become the main concern and emphasis in the management process of enterprise decision makers.

At present, domestic researches on technical efficiency mainly include parametric estimation and non-parametric estimation. The parametric method is mainly represented by the Stochastic Frontier Analysis method (SFA) proposed by Aigner et al. and Meeusen et al. The non-parametric method is mainly represented by the Data Envelope Analysis method (DEA) proposed by Charnes and Cooper. This paper focuses on the stochastic frontier production function model. The data are panel data from China for six consecutive years from 2010 to 2015. This article will focus on the current status of Chinese Aerospace manufacturing efficiency. Through quantitative analysis, explore the factors that affect the efficiency of Chinese Aerospace manufacturing industry. And find out the main factors that affect the efficiency of technology. According to the results of empirical analysis, this article puts forward relevant countermeasures (Aigner et al., 1977; Charnes et al., 1979; Meeusen \& Broeck, 1977).

Finally, it will also provide a reference for the government to formulate the development strategy of the aerospace manufacturing industry, the rational allocation of resources and the management of the aerospace manufacturing industry.

\section{Research Methods and Research Design}

Stochastic Frontier Analysis (SFA) was first proposed by Aigner, Lovell, Schmidt (1977) and Meeusen, Broeck (1977). The main feature of SFA is that the error term is divided into two parts when setting the model: one is a random error term, which indicates the influence caused by all uncontrollable factors, and the other is called an inefficiency term. Since the DEA method does not consider the error caused by the measurement, it is considered that all the random errors come from the efficiency difference. So the average efficiency deviation is rela- 
tively large. While, SFA fully considers this issue, and the estimation result is better in this regard. Therefore, this article will choose the SFA method as the analysis framework of this article (Aigner et al., 1977; Subal \& Knox Lovell, 2000; Tim et al., 2005; Shao \& Dang, 2007).

The SFA model used in this article is the production function model (called the B-C model) proposed by Battese and Coelli in 1992 and 1995, respectively. Compared with model B-C (1992), the B-C (1995) model incorporates the efficiency of imaging technology, so it is more suitable for the analysis of panel data (Battese \& Coelli, 1992, 1995).

\subsection{Model Construction}

This paper constructs the B-C (1995) model and analyzes it using Translog Production Functions. The model is built as follows:

$$
\begin{aligned}
\ln \left(Y_{i t}\right)= & \beta_{0}+\beta_{1} \ln \left(L_{i t}\right)+\beta_{2} \ln \left(K_{i t}\right)+\beta_{3} \ln \left(L_{i t}\right)^{2} \\
& +\beta_{4} \ln \left(K_{i t}\right)^{2}+\beta_{5}\left[\ln \left(L_{i t}\right) * \ln \left(K_{i t}\right)\right]+v_{i t}-u_{i t} \\
m_{i t}= & \delta_{0}+\delta_{1} z_{1 t}+\delta_{2} z_{2 t}+\delta_{3} z_{3 t}+\delta_{4} z_{4 t}+\delta_{5} z_{5 t}
\end{aligned}
$$

among them: $i=1,2, \cdots, N ; t=1,2, \cdots, T$.

Equation (1) is a specific production function. In Equation (1), $Y_{i t}$ represents the output of $i$ regions in the t period. $L_{i t}$ represents the labor input in area $i$ during period $t . K_{i t}$ represents the capital input of $\mathrm{i}$ regions in the $t$ period. $v_{i t}$ represents a random perturbation term. We assume that $v_{i t}$ follows the $N\left(0, \sigma_{v}^{2}\right)$ distribution and it is independent of $u_{i t} \cdot u_{i t}$ represents the technical inefficiency term, which is a non-negative random variable that obeys the $N\left(m_{i t}, \sigma_{u}^{2}\right)$ distribution with a truncation of 0 points.

Equation (2) is the efficiency model for $m_{i t}$. Among them, the larger $m_{i t}$ is, the lower the technical efficiency is. And $z_{i t}$ in the model represent various factors that affect efficiency, and $\delta_{i}$ represents the parameters to be estimated.

Further, considering the calculation of the maximum likelihood estimation, we define the following indicators to measure the effectiveness of the stochastic frontier function: $\gamma=\frac{\sigma_{u}^{2}}{\sigma_{v}^{2}+\sigma_{u}^{2}}$ (Battese \& Coelli, 1992, 1995).

It is clear that $\gamma \in[0,1]$. And the larger the value $\gamma$, the more obvious the effect of the factors causing inefficiency. If $\gamma=0$, it means that there is no inefficient term. At this time, it can be directly estimated by the Least Square Method.

\subsection{Data Source and Parameter Meaning}

The data in this article comes from the Statistical Yearbook of Chinese High-Tech Industry (2011-2016 edition). This paper selected 17 important regions in 31 provinces and cities in China and constructed panel data for analysis, including relevant data for 6 consecutive years from 2010 to 2015. Due to imperfect statistics or because they do not belong to the development area of the 
national aerospace manufacturing industry, the remaining 14 provinces and autonomous regions have less industrial investment. The local support is not strong enough. This leads to imperfect data, so Hebei, Shanxi, Inner Mongolia, Jilin, Fujian, Guangxi, Hainan, Chongqing, Yunnan, Tibet, Qinghai, Ningxia, and Xinjiang are not included in the scope of this article.

In Equation (1), $Y_{i t}$ represents the total output of the aerospace manufacturing industry. The main output data of the provinces and autonomous regions on aerospace manufacturing from 2010 to 2015 are used to reflect the total output, and the unit is 100 million yuan. $L_{i t}$ represents the average annual number of employees in the aerospace manufacturing industry, the unit is person; $K_{i t}$ represents the total assets of the aerospace manufacturing industry at the end of the year, and the unit is 100 million yuan.

In Equation (2), $z_{1 t}$, the influencing factors, represent the export delivery value of the aerospace manufacturing industry, the unit is 100 million yuan. The influencing factors $z_{2 t}$ represent the R \& D personnel equivalent to full-time equivalent in the aerospace manufacturing industry, and the unit is person-year. The influencing factors $z_{3 t}$ represent the internal expenditures of $\mathrm{R} \& \mathrm{D}$ funds for the aerospace manufacturing industry. The unit is 10,000 yuan. The influencing factor $Z_{4 t}$ represents the sales revenue of new products of the aerospace manufacturing industry. The unit is 10,000 yuan. The influencing factor $z_{5 t}$ represents the annual increase of fixed assets in the aerospace manufacturing industry. The unit is 100 million yuan.

\section{Technical Efficiency: Empirical Analysis}

\subsection{Parameter Estimation Results of the Stochastic Boundary Model}

This paper uses the software Frontier 4.1 to estimate the parameters of the aerospace manufacturing related data of 17 provinces and cities in China from 2010 to 2015. The results are shown in Table 1 .

Table 1 shows the estimation results of the production function and technical efficiency function of Chinese Aerospace manufacturing industry. The results of the production function section in Table 1 show that among the 6 variables including the intercept term in the production function, except for $\ln L^{2}$, which did not pass the statistical test, the other 5 variables all passed the significance level of $1 \% \mathrm{~T}$ test. As can be seen from the part of the variance coefficient, the estimated value of $\gamma$ after the model estimation is about 0.9068 , which exceeds 0.5. And the corresponding $L R$ statistical value is 69.79616 , which is statistically significant at a significance level of $1 \%$, so the model passes the test. Therefore, in terms of aerospace manufacturing, technological inefficiency is relatively significant.

\subsection{Analysis of Influencing Factors of Technical Efficiency}

Then we analyze the technical efficiency of the aerospace manufacturing industry. From the results of the partial efficiency function in Table 1, we can find: 
Table 1. Estimation results of technical efficiency parameters for aerospace manufacturing.

\begin{tabular}{|c|c|c|c|c|}
\hline \multicolumn{2}{|c|}{ Variable } & \multirow{2}{*}{$\begin{array}{c}\text { Parameter estimates } \\
1.0274\end{array}$} & \multirow{2}{*}{$\begin{array}{c}\text { St.d } \\
0.3984\end{array}$} & \multirow{2}{*}{$\begin{array}{c}\text { T-test value } \\
2.5790^{* * *}\end{array}$} \\
\hline \multirow{6}{*}{$\begin{array}{l}\text { Production } \\
\text { function }\end{array}$} & $\ln L$ & & & \\
\hline & $\ln K$ & 0.6216 & 0.2342 & $2.6547^{* * *}$ \\
\hline & $\ln L^{2}$ & 0.0012 & 0.0294 & 0.0417 \\
\hline & $\ln K^{2}$ & 0.1793 & 0.0397 & $4.5214^{* * *}$ \\
\hline & $\ln L * \ln K$ & -0.1657 & 0.0505 & $-3.2832^{* * *}$ \\
\hline & Cons__ & -5.0832 & 1.5243 & $-3.3349^{* * *}$ \\
\hline \multirow{6}{*}{$\begin{array}{l}\text { Efficiency } \\
\text { function }\end{array}$} & $z_{1}$ & -0.0096 & 0.0090 & -1.0709 \\
\hline & $z_{2}$ & -0.0008 & 0.0002 & $-3.7820^{* * *}$ \\
\hline & $Z_{3}$ & 0.0000 & 0.0000 & -1.3639 \\
\hline & $Z_{4}$ & 0.0000 & 0.0000 & 0.2065 \\
\hline & $z_{5}$ & -0.0119 & 0.0039 & $-3.0805^{* * *}$ \\
\hline & Cons_ & -6.9221 & 2.0266 & $-3.4157^{* * *}$ \\
\hline Variance & $\sigma^{2}$ & 0.7789 & 0.1248 & $6.2389^{* * *}$ \\
\hline Coefficient & $\gamma$ & 0.9068 & 0.0264 & $34.2872^{* * *}$ \\
\hline
\end{tabular}

Note: Among them, $\sigma^{2}=\sigma_{u}^{2}+\sigma_{v}^{2}{ }^{* * *}$ represents statistically significant at a significance level of $1 \%$. Log Likelihood Function $=-27.7729$, LR test of the one-sided error $=69.7962^{* * *}$.

The coefficient $\delta_{1}$ of $z_{1 t}$ is not significant at the significance level of $1 \%$, and the statistical significance is low. Export delivery value is an important indicator for measuring the products of industrial enterprises entering the international market. It is also a major indicator for the integration of Chinese large industrial enterprises into the world economy. According to the results estimated by Zhang Jinle and Liu Tian (2012): The export delivery value has a positive relationship with the technical efficiency of the aerospace manufacturing industry and the statistics show that it is statistically significant. With the current six-year data, compared to 2001-2009, the impact of export delivery on technical efficiency has become less significant. This also shows that increasing export delivery at this stage cannot greatly improve the technological efficiency of the aerospace manufacturing industry (Zhang \& Liu, 2012).

The coefficient $\delta_{2}$ of $z_{2 t}$ is statistically significant at a significance level of $1 \%$, and it is negative. This shows that the full-time equivalent of $\mathrm{R} \& \mathrm{D}$ personnel in the aerospace manufacturing industry has a significant positive impact on the technical efficiency of the aerospace manufacturing industry. R \& D personnel full-time equivalent is an internationally used indicator for comparing scientific and technological manpower inputs. As the full-time equivalent of R \& D personnel increases, it also means that more and more scientific and technological manpower is invested in aerospace manufacturing, which will increase the possibility of $\mathrm{R} \& \mathrm{D}$ innovation. Therefore, it has played a positive role in improving the technical efficiency of the aerospace manufacturing industry.

The coefficient $\delta_{3}$ of $z_{3 t}$ is not significant at the significance level of $1 \%$, and the statistical significance is low. Although the statistical significance is low, 
and it is a negative value, which indicates to some extent that the internal expenditure of $\mathrm{R} \& \mathrm{D}$ funds has a positive effect on the improvement of technological efficiency. Part of the insignificant reasons may be that Chinese current higher education talents are not sufficient, and the scientific research force is not strong enough, which has led to the government's scientific research funding being not fully used for its purposes (Chen et al., 2012).

The coefficient $\delta_{4}$ of $z_{4 t}$ is not significant at the significance level of $1 \%$, and the statistical significance is low. This shows that the revenue from new product sales does not significantly improve the technological efficiency of the aerospace manufacturing industry. The sales situation of new products reflects Chinese scientific research results to a certain extent, and it is a manifestation of $\mathrm{R} \& \mathrm{D}$ expenditures. In theory, excellent research and development teams, continuous innovation technology and products that are in line with the aerospace manufacturing industry are all guarantees to improve technical efficiency. According to empirical results, Chinese current level of scientific research is not strong enough, and the competitiveness of products in the world market is relatively insufficient. Therefore, China should continue to increase R \& D investment in China's aerospace manufacturing industry. Enhance innovation and improve product competitiveness (Liu, 2013).

The coefficient $\delta_{5}$ of $z_{5 t}$ is statistically significant at a significance level of $1 \%$, and it is negative, which indicates that the increase of new fixed assets in the aerospace manufacturing industry has a positive impact on improving the technical efficiency of the industry. And the positive effect is more significant. The increase in new fixed assets represents the gradual expansion of the enterprise, more complete and advanced equipment. Coupled with the input suitable for the production of specified assets, it is conducive to improving technological efficiency.

\subsection{Analysis of Technical Efficiency Differences by Region}

According to the B-C (1995) model, calculation was performed using the software Frontier 4.1. The technical efficiency values of the aerospace manufacturing industry in Chinese 17 provinces and cities in different years can be obtained. The results are shown in Table 2. It can be seen from the technical efficiency values of different years in different regions in Table 2.

As far as these 17 provinces and cities are concerned, the total average technical efficiency of Chinese Aerospace manufacturing industry $\overline{Y n}$ is 0.8673 over the past 6 years. This shows to a certain extent that the technical efficiency of the aerospace manufacturing industry is at a moderately high level. The efficiency level of the aerospace manufacturing industry is gradually approaching that of computer and office equipment manufacturing and other manufacturing industries with technological efficiency close to one. Because the sample selected in this paper only includes 17 provinces and cities, 14 provinces and cities are not included. Therefore, Chinese Aerospace manufacturing industry still has a lot of room for technological progress (Yu \& Wu, 2010). 
Table 2. Technical efficiency values of aerospace manufacturing by province.

\begin{tabular}{cccccccc}
\hline Area & 2010 & 2011 & 2012 & 2013 & 2014 & 2015 & $\overline{Y n}$ \\
\hline Beijing & 0.8842 & 0.8635 & 0.8922 & 0.8894 & 0.8833 & 0.8973 & 0.8850 \\
Tianjin & 0.9148 & 0.9108 & 0.9161 & 0.9258 & 0.9399 & 0.9049 & 0.9187 \\
Liaoning & 0.9105 & 0.9098 & 0.8921 & 0.8693 & 0.9028 & 0.9077 & 0.8987 \\
Heilongjiang & 0.8804 & 0.8902 & 0.9020 & 0.9065 & 0.9154 & 0.8894 & 0.8973 \\
Shanghai & 0.8500 & 0.8797 & 0.9084 & 0.8821 & 0.9089 & 0.8825 & 0.8853 \\
Jiangsu & 0.9023 & 0.9463 & 0.9483 & 0.9216 & 0.9411 & 0.9512 & 0.9351 \\
Zhejiang & 0.9017 & 0.8898 & 0.8913 & 0.9133 & 0.9167 & 0.8919 & 0.9008 \\
Anhui & 0.9096 & 0.9162 & 0.9193 & 0.9138 & 0.8918 & 0.9040 & 0.9091 \\
Jiangxi & 0.7976 & 0.8500 & 0.8046 & 0.8261 & 0.9187 & 0.9241 & 0.8535 \\
Shandong & 0.8952 & 0.9172 & 0.9095 & 0.9127 & 0.9487 & 0.9479 & 0.9219 \\
Henan & 0.9040 & 0.9136 & 0.8969 & 0.8294 & 0.8823 & 0.9000 & 0.8877 \\
Hubei & 0.8733 & 0.8902 & 0.8866 & 0.8709 & 0.9051 & 0.9138 & 0.8900 \\
Hunan & 0.8618 & 0.8855 & 0.9248 & 0.9057 & 0.9170 & 0.8997 & 0.8991 \\
Guangdong & 0.9409 & 0.8179 & 0.8389 & 0.8442 & 0.9496 & 0.9482 & 0.8899 \\
Sichuan & 0.9053 & 0.8961 & 0.8962 & 0.8885 & 0.9032 & 0.8784 & 0.8946 \\
Guizhou & 0.8085 & 0.8225 & 0.8352 & 0.7786 & 0.7276 & 0.7581 & 0.7884 \\
Shaanxi & 0.7363 & 0.7433 & 0.6868 & 0.0951 & 0.6435 & 0.0324 & 0.4896 \\
$\overline{\text { Ym }}$ & 0.8751 & 0.8790 & 0.8794 & 0.8337 & 0.8880 & 0.8489 & 0.8673 \\
\hline
\end{tabular}

Note: $\overline{Y m}$ represents the annual average, and $\overline{Y m}$ represents the regional average.

Secondly, from the average technical efficiency in different years, it can be seen that the annual average technical efficiency of the aerospace manufacturing industry does not increase steadily over time. It is in a state of ups and downs. At present, the highest technical efficiency was in 2014, with a technical efficiency value of 0.8880 . The lowest was 0.8337 in 2013 . The degree of fluctuation in the next two years is relatively large, which indicates that the instability of the technical efficiency of Chinese Aerospace manufacturing industry is relatively strong.

Third, from the perspective of national regional division, the technical efficiency value of the aerospace manufacturing industry in most parts of eastern and central China is significantly higher than that in the western region. Eastern regions such as Liaoning, Heilongjiang, Beijing, Tianjin, etc. have relatively high investment in scientific research funds, high-tech personnel, and new fixed assets for products. Therefore, its aerospace manufacturing industry has developed relatively well and its technical efficiency is relatively high. However, due to differences in landforms, human, material and financial resources, the technical efficiency of the western region is relatively low. While, there are also provinces and cities with high technological efficiency in the western region. For example, the technological efficiency of the aerospace manufacturing industry in Sichuan Province is as high as 0.8946 . 


\section{Conclusions and Recommendations}

Through the above calculations and analysis, the following conclusions can be drawn and corresponding suggestions are made:

As a whole, in terms of the 17 provinces and cities selected in the sample, the estimated output of Chinese Aerospace manufacturing industry is relatively good. The average technical efficiency reached 0.8673 . But for all provinces and cities in China, the technical efficiency of the aerospace manufacturing industry has not yet reached the optimal state. There is still much room for improvement. Therefore, all provinces and cities should continue to increase scientific and technological innovation. Propose some related incentive policies for scientific research innovation. Increase investment in efficient labor and capital. Actively promote the transformation of scientific research results into actual productivity. In the end, we must avoid the trap of high input and low output, and effectively increase the input-output ratio of the enterprise (Wang \& Gu, 2015).

China still needs to continue to increase its investment in technological innovation in the aerospace manufacturing industry, a high-tech industry, and expand the scale of industrial innovation.

In increasing the input of human resources, more attention should be paid to improving the efficiency of resource allocation for high-quality talents. This guarantees the company's continuous innovation ability and improves the use of $\mathrm{R} \& \mathrm{D}$ funds. Then gradually increase the international competitiveness of the product. In order to achieve better results, provinces and cities can set up reward and responsibility mechanisms for talent introduction and use. Continuously strengthen the training of talents. Improve the frequency and quality of cutting-edge talent exchanges. Learn and develop advanced technologies. And continuously increase the number of high-quality talents (Ding \& Chen, 2016).

In terms of increasing material resources, appropriately increase new fixed assets to improve the production efficiency of enterprises. At the same time, formulate requirements for the use of scientific research funds, standardize the use of funds, and gradually strengthen Chinese scientific research results. And further improve the level of technical efficiency of Chinese Aerospace manufacturing industry (Zhang\& Zhao, 2014).

Aerospace manufacturing belongs to the high-tech industry. While enterprises are constantly improving their technical level, they cannot ignore the importance of improving their management level. Therefore, we should continuously improve innovative technologies and seek technological breakthroughs. Continuously learn and introduce advanced management models to master efficient management experience. On the basis of focusing on management innovation, we must keep open to the outside world and develop an export-oriented economy. Only in this way can Chinese aerospace manufacturing complete efficient development on the basis of rapid development.

This article only considers 17 important regions in 31 provinces and cities in China. Therefore, the research conclusions need to be studied for the remaining 
14 provinces and autonomous regions. And the recommendations made had certain limitations. In the future extended research, more comprehensive data of provinces and cities in China will be further selected to make the research conclusions more applicable.

\section{Conflicts of Interest}

The author declares no conflicts of interest regarding the publication of this paper.

\section{References}

Aigner, D. J., Lovell, C. A. K., \& Schmidt, P. (1977). Formulation and Estimation of Stochastic Frontier Production Function Models. Journal of Econometrics, 1, 21-37. https://doi.org/10.1016/0304-4076(77)90052-5

Battese, G. E., \& Coelli, T. J. (1992). Frontier Production Functions Technical Efficiency and Panel Data with Application to Paddy Famer in India. Journal of Productivity Analysis, 3, 153-169. https://doi.org/10.1007/BF00158774

Battese, G. E., \& Coelli, T. J. (1995). A Model for Technical Inefficiency Effects in a Stochastic Frontier Production Function for Panel Data. Empirical Economics, 20, 325-332. https://doi.org/10.1007/BF01205442

Charnes, A., Cooper, W., \& Rhodes, E. (1979). Measuring the Efficiency of Decision Making Units. European Journal of Operational Research, 7, 429-444. https://doi.org/10.1016/0377-2217(79)90229-7

Chen, K. H., Guan, J. C., \& Kou, M. T. (2012). The Crux and Countermeasures of High Output and Low Efficiency in China's High-Tech Industry an Exploration from the Perspective of Technological Innovation Efficiency. Management Review, 4, 53-66.

Ding, Y., \& Chen, K. (2016). Research on Innovation Efficiency and Influencing Factors of China Aviation Manufacturing Industry. Journal of Xi'an Aeronautical Institute, 4, 3-8.

Liu, P. L. (2013). Empirical Analysis of Innovation Efficiency in Aerospace Manufacturing Based on Stochastic Frontier Analysis. Journal of Xi'an University of Finance and Economics, 2, 93-97.

Meeusen, W., \& Broeck, J. (1977). Efficiency Estimation from Cobb-Douglas Production Functions with Composed Error. International Economic Review, 2, 435-444.

Shao, Y. F., \& Dang, Y. (2007). Research on the Regional Technical Innovation Efficiency of Chinese Aerospace Manufacturing Based on the DEA-Malmquist Method. Science and Technology and Industry, 6, 1-7.

Subal, C. K., \& Knox Lovell, C. A. (2000). Stochastic Frontier Analysis (pp. 8-11). Cambridge: Cambridge University Press..

Tim, C., Prasada Rao, D. S., Christopher, J. O., \& Donnell, G. E. B. (2005). An Introduction to Efficiency and Productivity Analysis (pp. 271-280). New York: Springer.

Wang, M., \& Gu, S. Z. (2015). Empirical Analysis of the Technological Innovation Capability of China's High-Tech Industry. China Science and Technology Forum, 3, 67-73.

Yu, Y. Z., \& Wu, P. (2010). Empirical Research on the Efficiency of China's Logistics Industry and Its Influencing Factors Analysis of Stochastic Frontier Production Functions Based on Provincial Data in China. Industrial Economics Research, 1, 65-71.

Zhang, J. L., \& Liu, T. (2012). Analysis of Technical Efficiency of Chinese Aerospace 
Manufacturing Based on SFA. Theory and Practice of Finance and Economics, 1, 95-103.

Zhang, J. L., \& Zhao, J. (2014). Study on the Environmental Impact Factors of Scientific and Technological Innovation Capabilities of Chinese Aerospace Manufacturing Industry-A Path Analysis Based on Structural Equation Model. Journal of Beijing Institute of Technology Social Science Edition, 3, 100-106. 